\title{
Corrigendum
}

\section{Corrigendum to "Surfaces and Air Bacteriology of Selected Wards at a Referral Hospital, Northwest Ethiopia: A Cross-Sectional Study"}

\author{
Hailu Getachew, ${ }^{1}$ Awoke Derbie ${ }_{(D)}{ }^{2,3}$ and Daniel Mekonnen ${ }^{2}{ }^{2}$ \\ ${ }^{1}$ Amhara Public Health Institute (APHI), Bahir Dar, Ethiopia \\ ${ }^{2}$ Department of Medical Microbiology, College of Medicine and Health Sciences, Bahir Dar University, Bahir Dar, Ethiopia \\ ${ }^{3}$ Center for Innovative Drug Development \& Therapeutic Trials for Africa (CDT-Africa), Addis Ababa University, \\ Addis Ababa, Ethiopia
}

Correspondence should be addressed to Awoke Derbie; awe.love2000@gmail.com

Received 26 June 2018; Accepted 9 July 2018; Published 29 July 2018

Copyright (c) 2018 Hailu Getachew et al. This is an open access article distributed under the Creative Commons Attribution License, which permits unrestricted use, distribution, and reproduction in any medium, provided the original work is properly cited.

In the article titled "Surfaces and Air Bacteriology of Selected Wards at a Referral Hospital, Northwest Ethiopia: A CrossSectional Study" [1], there was a missing affiliation for the second author. The corrected authors' list and affiliations are shown above.

\section{References}

[1] H. Getachew, A. Derbie, and D. Mekonnen, "Surfaces and air bacteriology of selected wards at a referral hospital, Northwest Ethiopia: a cross-sectional study," International Journal of Microbiology, vol. 2018, Article ID 6413179, 7 pages, 2018. 


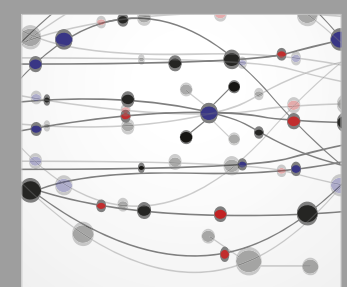

The Scientific World Journal
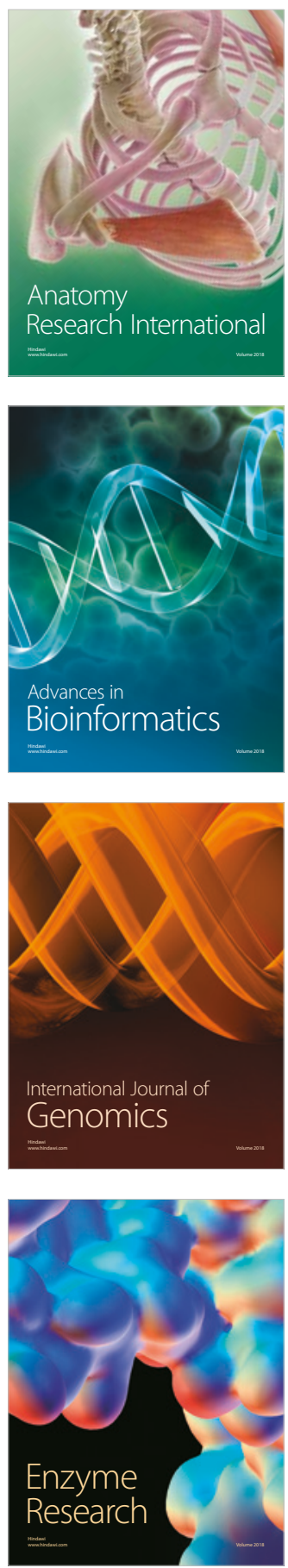
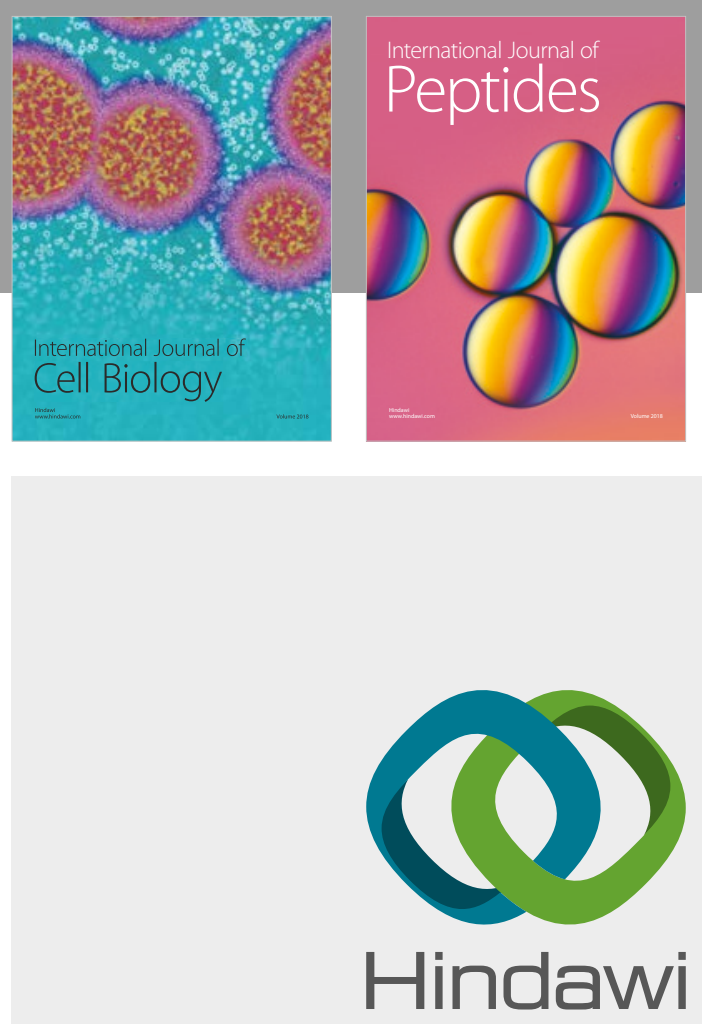

Submit your manuscripts at

www.hindawi.com
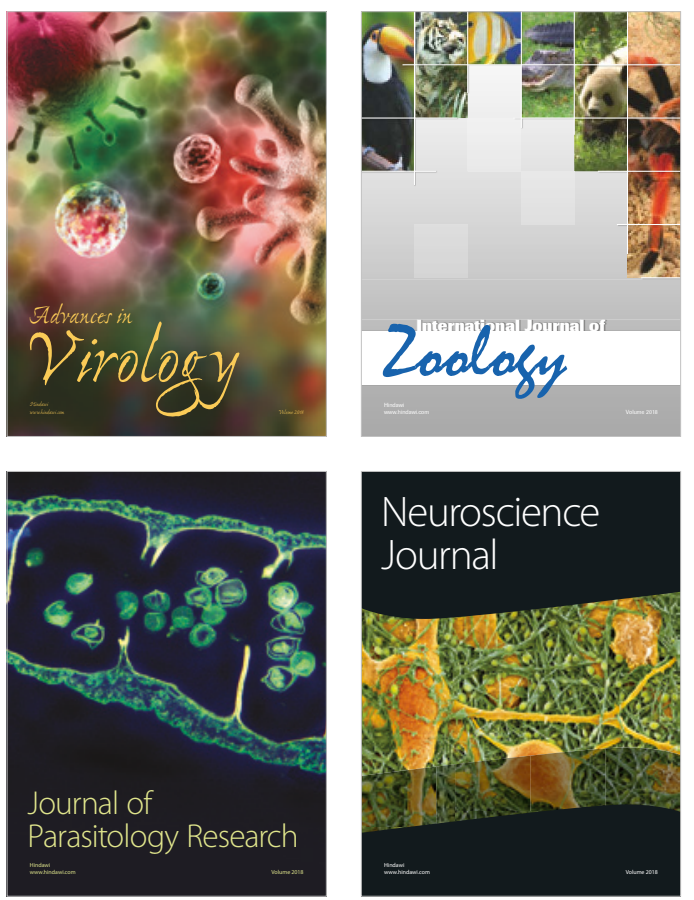
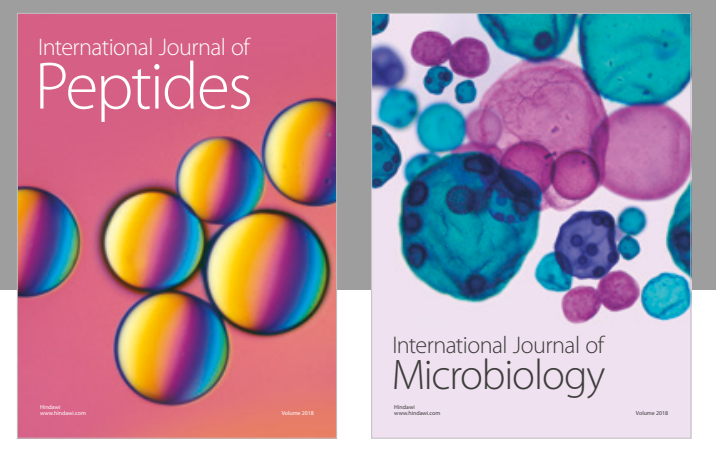

nternational Journal of Microbiology
Journal of
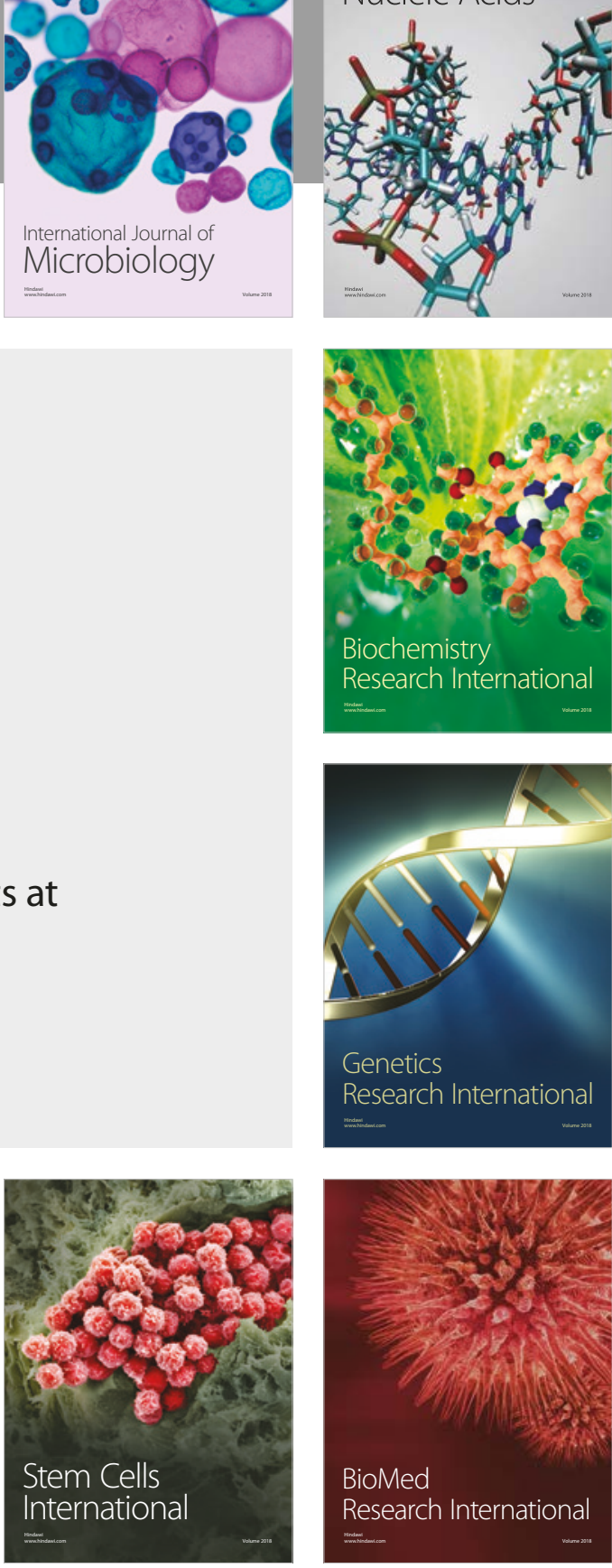
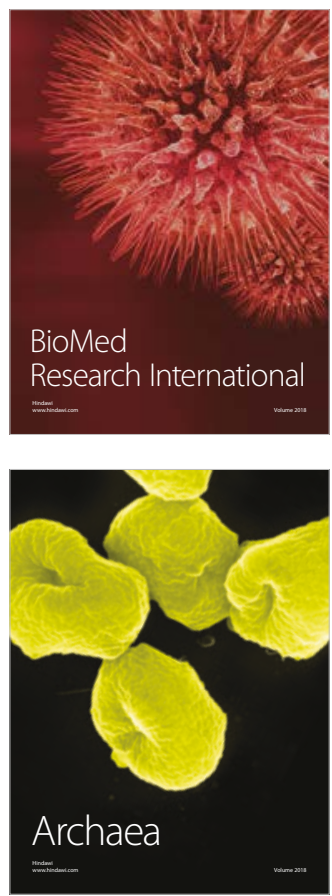